\title{
Proposta para Implementar Avaliação Formativa no Ensino Médio
}

\section{A Proposal to Implement Formative Assessment in High School}

\author{
Fabiana Carvalho Silva' \\ Ana Carolina S. A. Carvalho \\ Mateus Ligabo \\ Durval Rodrigues Jr. \\ Rita C. L. B. Rodrigues \\ 1Universidade de São Paulo (USP), Escola de Engenharia de Lorena (EEL), Lorena, SP, Brasil.
Autora correspondente: : rita@debiq.eel.usp.br
}

Resumo: Esta proposta baseou-se no modelo estrutural para análise da avaliação formativa, composto por processos inter-relacionados: comunicação de expectativas e critérios de sucesso; obtenção, coleta e interpretação de informações; fornecimento de feedback; e regulação da aprendizagem. Para ajudar o professor na implementação da avaliação formativa, articularam-se, com esses processos, as práticas: metodologia de aprendizagem baseada em problemas (ABP) e dimensões culturais de Hofstede. Durante um semestre e meio avaliou-se estatisticamente o desempenho de 55 estudantes. Competências e habilidades foram avaliadas em situações-problemas retiradas do Exame Nacional do Ensino Médio. O perfil cultural foi determinado pelo questionário Value Survey Model 1994. Como resultado observou-se melhora no desempenho acadêmico $(p<0,05)$ e no comportamental dos estudantes $(p<0,05)$. Porém, como a atribuição de nota é exigência do sistema, a postura avaliativa percorreu um nível intermediário entre classificatória e formativa. Formulários de apoio incluídos no plano pedagógico da escola favoreceram a prática de avaliação formativa.

Palavras-chave: Ensino de biologia; Avaliação formativa; Aprendizagem baseada em problemas; Método da problematização; Ensino médio.

Abstract: This proposal was based on a structural model for analyzing formative assessment that is composed of interrelated processes: communication of expectancies and success criteria, elicitation, collection and interpretation of information, provision of feedback, and regulation of learning. To help the teacher in the implementation of formative assessment, specific practices were articulated with those processes, namely the problem-based learning (PBL) methodology and Hofstede's cultural dimensions. For one semester and a half, the performance of 55 students was statistically evaluated. Competences and abilities were assessed in problem situations taken from Exame Nacional do Ensino Médio, and the cultural profile was determined by the Value Survey Model 1994 questionnaire. As a result, there was an improvement in both students' academic performance $(p<0.05)$ and behavioral performance $(p<0.05)$. However, as rating is a requirement in the system, the evaluation was at an intermediate degree between classificatory and formative. Supportive feedback forms included in the school's pedagogical plan favored the practice of formative assessment.

Keywords: Teaching of biology; Formative assessment; Problem-based learning; Questioning method; High school.

Recebido em: 24/03/2019

Aprovado em: 12/11/2019 


\section{Introdução}

A cultura tradicional, na qual os estudantes desempenham o papel passivo e os professores o papel ativo, dificulta mudanças no ensino em sala de aula (HARRES, 2016). Apesar de uma cultura alternativa estar se desenvolvendo em sala de aula, muitos professores, que não vivenciaram em sua formação experiências alternativas, pouco provavelmente começarão a praticá-la mais tarde (ESTRELA; NÓVOA, 2003). Desta forma, a avaliação ressalta-se como problema e como conflitos antigos, apresentando defasagem em seu nível de desenvolvimento investigativo com relação a outros aspectos do ensino (HARRES, 2016).

De acordo com Sant'Anna (1995), a avaliação se divide em três tipos: diagnóstica, formativa e classificatória. Na avaliação diagnóstica, verificam-se os conhecimentos e obtêm-se as informações do rendimento do estudante, enquanto, na avaliação formativa, ocorre o acompanhamento progressivo do estudante, ajudando-o no desenvolvimento de suas capacidades cognitivas, ao mesmo tempo em que fornece informações sobre o seu desempenho. Já, na avaliação classificatória, tida como somativa, classifica-se o estudante segundo o seu rendimento escolar, buscando a consciência coletiva dos resultados apresentados pelos estudantes.

A educação em valores é uma realidade da Lei de Diretrizes e Bases 9.394/96, a LDB (ou Lei Darcy Ribeiro), que, ao se referir à verificação do conhecimento escolar, determina que sejam observados os critérios de avaliação contínua e cumulativa da atuação do educando, com prioridade dos aspectos qualitativos sobre os quantitativos e dos resultados ao longo do período sobre os de eventuais provas finais (BRASIL, 2014). Uma avaliação contínua e diversa integra-se ao processo ensino-aprendizagem e é sensível o suficiente para deflagrar mudanças de atitudes nos estudantes (BARROS FILHO; SILVA, 2000).

No ensino de biologia, a mudança de atitudes dos estudantes está em compreender as relações conceituais - tais como de célula para célula, de organismo para célula - e as relações intracelulares. Essas relações conceituais compreendem a célula como um fenômeno não estático, e sim como um sistema dinâmico que interage com seus componentes (RODRÍGUEZ PALMERO; MOREIRA, 1999). Para facilitar essa compreensão, dentre as modalidades de trabalhos práticos, tem-se a aprendizagem baseada em problemas (ABP) que é uma modalidade de trabalho pedagógico que se insere no campo das metodologias ativas de aprendizagem prática, conforme Barros Filho e Silva (2000). De acordo com esses autores, sua adoção é comum em cursos superiores e não há impedimentos para usá-la, também, com estudantes mais jovens. O ponto de partida é sempre um problema definido por docentes ou, então, por grupos de estudantes que elaboram uma questão - sobre problemas concretos e reais - para investigar.

Em diferentes propostas que adotam a ABP, a avaliação da aprendizagem é um tema relevante (HENDRY; FROMMER; WALKER, 1999). Para Harres (2016), a postura avaliativa situase em uma escala de complexidade crescente dos diferentes níveis de avaliação pela qual um professor pode desenvolver-se profissionalmente. Esse autor explicita que, nos níveis mais avançados nesta escala, não existe relação entre a avaliação e a atribuição de notas, porque estas não existem ou não são necessárias no processo educativo. 
Desta forma, Harres (2016) propõe uma escala estruturada na qual o Nível 1 represente o nível mais baixo de avaliação, centrada na memorização mecânica de conceitos, passe por diversos estágios intermediários e, conforme os pressupostos teóricos (uma perspectiva crítica, complexa, evolutiva e construtivista do conhecimento), alcance o Nível 7, que representa o estágio de referência desejável. A utilidade desta escala está em poder caracterizar diferentes posturas avaliativas, identificando, assim, quais níveis (e práticas) são evolutivamente mais coerentes com os pressupostos adotados, permitindo a definição de estratégias de evolução das posturas avaliativas (HARRES, 2016).

Conforme Pérez Gómez (2001), a cultura escolar pode potenciar e até restringir a imaginação e a prática de quem a vive; portanto, considerar a maneira como as diferentes culturas são vividas, compartilhadas e respeitadas na escola pode ser determinante no desenvolvimento e na aprendizagem dos estudantes. Esses autores mencionam que as organizações escolares, por um processo constante de interação entre seus membros, estariam criando uma cultura orientadora das ações desses membros, sem, no entanto, constituir-se em um quadro estático. Assim, o grau de participação nas escolas se definiria em razão das concepções que seriam compartilhadas e construídas nesse processo de constituição da cultura escolar. O sentido da palavra compartilhada é o de que padrões comportamentais, valores, princípios e regras são seguidos até que novas formas sejam reelaboradas, reinterpretadas e implementadas pelo grupo (PAULA-SILVA, 2001).

O conceito de cultura organizacional foi transposto para a área de educação na década de 1970. Entre os vários estudiosos desse tema, Hofstede (1980) apresenta uma concepção de cultura como um fenômeno coletivo parcialmente compartilhado por pessoas que vivem ou viveram no mesmo ambiente social onde é adquirida. Este ambiente fornece regras não escritas (programação), que são aprendidas (processo cognitivo da mente) e se associam à personalidade individual. Para o autor, pode-se dizer que a cultura não pode ser compreendida e analisada fora dos contextos onde é produzida.

Para a análise comparativa das culturas nacionais, Hofstede (1994) é conhecido por seu conjunto de cinco dimensões, permitindo estabelecer comparações entre elas. As cinco principais dimensões culturais de Hofstede (SANTANA; MENDES; MARIANO, 2014) são: (a) índice de distância hierárquica (PDI), que é a consequência da desigualdade como diferentes níveis de poder; todas as sociedades são desiguais, mas algumas são mais desiguais do que outras. Esta dimensão define o quanto a sociedade aceita a distribuição desigual de poder; (b) individualismo versus coletivismo (IDV), que é a medida do grau de vínculos entre as pessoas. Essa dimensão se reflete na autoimagem das pessoas, definida como o 'eu' e o 'nós'; (c) masculinidade versus feminilidade (MAS), em que o lado da masculinidade representa predominância, na sociedade, dos valores acenados historicamente aos homens - como agressividade, ambição, desejo de poder, entre outros. A feminilidade é uma preferência para cooperação, modéstia, cuidar dos mais frágeis e qualidade de vida; (d) índice de aversão à incerteza (UAI), que expressa o grau em que os membros de uma sociedade se sentem desconfortáveis perante a incerteza. Nesse contexto, países com alto grau de aversão à incerteza mantêm forte código de crenças e comportamentos; (e) orientação de longo prazo versus orientação normativa de curto prazo (LTO); esta dimensão está relacionada à expectativa de tempo de retorno em termos de recompensa e resultado de uma tarefa ou ação implementada que, de forma geral, os indivíduos de uma sociedade possuem. 
Antoniou e James (2014) estudaram a avaliação formativa implementada nas salas de aula no ensino fundamental, nos EUA, e desenvolveram um modelo estrutural de ação para analisar e entender os processos de avaliação formativa. A coleta de dados foi baseada em observações de não participantes da sala de aula, entrevistas com os professores e análise documental dos trabalhos das crianças. A análise dos dados foi constante e realizada pelo método comparativo e revelou uma sequência de cinco processos inter-relacionados em uma avaliação formativa: (1) comunicação de expectativas e critérios de sucesso, (2) obtenção e coleta de informações, (3) interpretação da informação/julgamento, (4) fornecimento de feedback e (5) ação/regulação da aprendizagem. Surpreendentemente, a análise também apontou a confusão decorrente das várias interpretações desses processos e as dificuldades em implementar uma avaliação efetivamente formativa em sala de aula.

Neste contexto, este estudo propõe práticas como a metodologia ABP e as dimensões culturais de Hofstede (1994), articuladas com os processos inter-relacionados de Antoniou e de James (2014), para ajudar o professor em sala de aula a implementar o processo de avaliação formativa. A postura avaliativa efetuada foi comparada com níveis (e práticas) da escala estruturada por Harres (2016).

\section{Metodologia}

A proposta baseou-se no modelo estrutural de ação para analisar e entender os processos de avaliação formativa de Antoniou e James (2014). Os 55 estudantes de biologia do segundo ano do ensino médio de uma escola estadual localizada na cidade de Lorena, São Paulo, que participaram nesta pesquisa pertenciam a duas turmas: Turma A (30 estudantes) e Turma B (25 estudantes). A seguir, tem-se uma explicação de como foi planejado cada processo.

\section{Processo 1: Comunicação de expectativas e critérios de sucesso}

Este processo tem como meta proporcionar critérios específicos para o menor nível aceitável de realização, contra o qual os objetivos de uma lição ou tarefa podem ser alcançados. Nesta proposta, empregou-se como critério de sucesso as competências e as habilidades em resolução de problemas, por meio da metodologia de ABP.

\section{Temas para a aplicação da metodologia ABP}

Os temas para a aplicação da metodologia ABP foram escolhidos conforme a proposta curricular do Estado de São Paulo para o segundo ano do ensino médio em biologia. $O$ caderno do professor foi utilizado durante o ano letivo. O caderno do professor/estudante do Estado de São Paulo (SÃO PAULO, 2011) propõe dois grandes temas:

a. Identidade dos seres vivos: organização celular e funções vitais básicas, com as seguintes situações de aprendizagem: (1) a organização celular da vida; (2) biomembranas e suas funções; (3) processos de obtenção de energia pelos seres vivos: fotossíntese e respiração celular; (4) núcleo celular.

b. Transmissão da vida e mecanismos de variabilidade genética: variabilidade genética e hereditariedade; com as seguintes situações de aprendizagem: (5) as ideias pré-mendelianas; (6) as ideias de Mendel; (7) o processo meiótico; (8) a família Brasil; (9) certo cromossomo $X$. 
As situações-problemas basearam-se na competência de área 4: compreender interações entre organismos e ambiente, em particular aquelas relacionadas à saúde humana, relacionando conhecimentos científicos, aspectos culturais e características individuais. As habilidades exigidas foram: habilidade 14: identificar padrões em fenômenos e processos vitais dos organismos e processos vitais dos organismos, como manutenção do equilíbrio interno, defesa, relações com o ambiente; e habilidade 13: reconhecer mecanismos de transmissão da vida, prevendo ou explicando a manifestação de características dos seres vivos.

A aplicação da ABP (quadro 1) envolveu as situações de aprendizagem 3, 4, 5, 6, 7 e 8 dos temas mencionados. Os problemas contendo essas situações de aprendizagem foram retirados do Exame Nacional do Ensino Médio (ENEM) e desestruturados para a aplicação da metodologia aprendizagem baseada em problemas (ABP).

\section{Processo 2: Obtenção e coleta de informações}

Neste processo, a observação é utilizada para coletar evidências avaliativas obtidas sobre o que os estudantes sabem, entendem e podem fazer, bem como sobre seu comportamento e interações. Nesta etapa, os professores devem evitar julgamentos. Nesta pesquisa, incluiu-se como ferramenta facilitadora, para o entendimento do comportamento e das interações dos estudantes, o perfil cultural pautado em Hofstede (2011). Para avaliação formativa, utilizou-se a metodologia de ABP com atividades realizadas em grupos e individualmente.

Nesses grupos focais, avaliaram-se as competências e as habilidades, apresentadas no processo 1, em resolução de problemas não estruturados, observando e questionando o grupo enquanto os estudantes trabalhavam, mas também intervindo para apoiar o aprendizado quando apropriado. Para esta etapa, elaborou-se a ficha de auxílio do professor (figura 1), durante as avaliações atitudinais, para facilitar a anotação rápida do desempenho dos estudantes durante a aplicação da metodologia ABP.

\section{Procedimentos para a aplicação da metodologia ABP}

\section{Elaboração da ficha de auxílio do professor durante as avaliações atitudinais}

A figura 1 apresenta a ficha de auxílio do professor durante as avaliações atitudinais quando foi aplicada a metodologia ABP. Nessa avaliação, cada integrante do grupo poderia ganhar até dois pontos. O professor observou os grupos de estudantes por cinco a dez minutos e fez anotações seguindo etapas do trabalho dos estudantes - ao iniciar as atividades e ao realizar as atividades. Para facilitar a coleta de dados, visto a sala ser composta por número muito grande de estudantes, somente anotou-se um $\boldsymbol{x}$ na coluna que menciona 'todos os membros' e, em caso de exceção, este estudante foi mencionado na coluna 'exceto'. 
Figura 1 - Ficha para avaliação atitudinal dos estudantes durante a aplicação da aprendizagem baseada em problemas

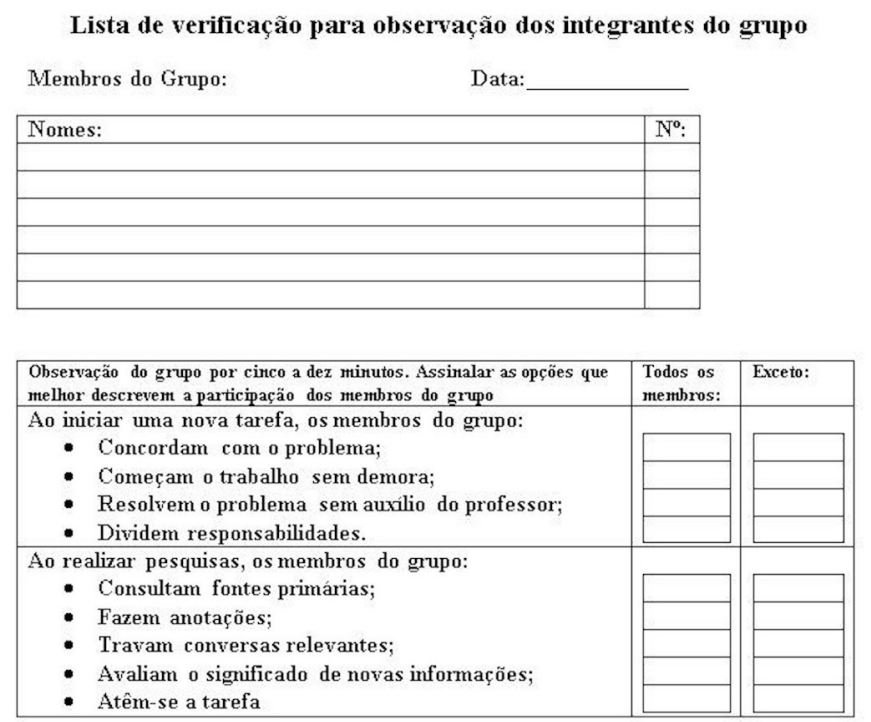

Fonte: Elaborada pelos autores.

\section{Estruturação para aplicação da metodologia Aprendizagem Baseada em Problemas (ABP)}

A estruturação da aplicação da metodologia ABP baseou-se no trabalho de Melo (2014). Para cada sequência de aprendizagem, foram utilizadas duas aulas para aplicação da metodologia ABP (as etapas da metodologia estão no quadro 1). Inicialmente, a professora ministrou uma breve aula sobre o tema, com auxílio de projetor multimídia. Depois, os estudantes, juntamente com a professora, foram para a sala de leitura da escola, que dispunha de mesas redondas. Cada mesa possuía acomodação para, no máximo, oito estudantes.

Foram formados grupos compostos por seis estudantes. Os estudantes receberam as questões-problemas referentes ao tema abordado. Estas questões foram apresentadas aos estudantes em dois momentos e de duas maneiras diferentes: (a) momento em grupo e de forma adaptada (formato não de múltipla escolha e com a exclusão de informações de fácil dedução de seus enunciados) e, na sequência, (b) momento individual e de forma original (como apresentado no ENEM). Na atividade em grupo (aplicação da ABP), foram cedidos aos estudantes diversos textos impressos sobre o assunto tratado durante a breve aula, para serem utilizados como fonte de pesquisa, argumentação e discussão.

O tempo para a resolução do exercício na ABP foi de 30 minutos. As notas foram atribuídas a cada estudante no formato de 'certo ou errado', de acordo com as competências envolvidas na atividade - os que não atingiram as competências exigidas foram pontuados com zero e os que conseguiram atingir essas competências receberam nota dez.

Quadro 1 - Estruturação da metodologia aprendizagem baseada em problemas

\begin{tabular}{|l|l|}
\hline Etapa & \multicolumn{1}{|c|}{ Descrição } \\
\hline 1 & Introduzir o problema no início das atividades, com breve aula \\
\hline 2 & Se o problema estiver escrito, prover cópia a todos os envolvidos \\
\hline 3 & Fornecer questões impressas a todos os membros \\
\hline 4 & $\begin{array}{l}\text { Se o problema estiver escrito em mais de uma página, fornecer uma de cada vez. O 'suspense' é bom motivador } \\
\text { de aprendizagem }\end{array}$ \\
\hline 5 & $\begin{array}{l}\text { Avaliar progressos em intervalos regulares. Se necessário, interromper os grupos para corrigir desvios e más inter- } \\
\text { pretações }\end{array}$ \\
\hline 6 & Permitir tempo para as discussões da classe ao fim de cada sessão ABP - Avaliações atitudinais \\
\hline
\end{tabular}

Fonte: Stanford, 2001 apud Melo, 2014, p. 78. 
Em tempos regulares e quando necessário, a professora (executora da pesquisa) interrompia os grupos para corrigir desvios e más interpretações relacionadas ao tema apresentado na ABP. Na sequência, foi proposto aos estudantes que, individualmente, resolvessem o mesmo exercício do ENEM na íntegra, ou seja, com as respostas do tipo múltipla escolha. O tempo para esta atividade foi de 15 minutos. O tempo total para essas atividades correspondeu ao tempo da aula de 50 minutos. Foi aplicado um problema por bimestre, considerando a metodologia ABP, totalizando três problemas (SILVA, 2017).

\section{Processo 3 e 4: Interpretação da informação e fornecimento de feedback}

De acordo com Antoniou e James (2014), o julgamento das atitudes dos estudantes e o fornecimento de feedback são muito importantes para indicar o nível de realização necessário para construir a estrutura de referência para autoavaliação. Nesta proposta, a interrelação entre os processos 3 e 4, do modelo estrutural de ações e estratégias para analisar a avaliação formativa foi facilitada com o conhecimento do perfil cultural dos estudantes obtido a partir do questionário Value Survey Model 1994 (VSM 94), que direcionou a conduta do professor no julgamento das atitudes dos estudantes e no fornecimento de feedback.

Também como ferramentas facilitadoras, foram elaboradas as fichas de acompanhamento do professor para ajudar nas anotações do total de pontos atingidos durante todas as atividades (ABP, avaliação bimestral e avaliação atitudinal), bem como a ficha de avaliação do estudante, que pôde registrar e acompanhar seu desempenho durante as aulas e as atividades propostas e realizar sua autoavaliação.

\section{Elaboração da ficha de acompanhamento do professor}

O modelo adaptado da ficha de acompanhamento do professor teve como base o trabalho de Muniz e Santinho (2007). Esta ficha contém os números dos estudantes, espaço para especificar a série e o bimestre e espaço para a anotação do total de pontos atingidos durante todas as atividades (ABP, avaliação bimestral e avaliação atitudinal). As avaliações envolveram a utilização de pontos, ao invés de notas, que foram atribuídos aos estudantes e convertidos em notas ao final do bimestre. A relação entre pontos e notas foi realizada da seguinte maneira:

- Uma avaliação formativa baseada em problema (ABP), em grupo, valendo cinco pontos e, individualmente, valendo mais cinco (totalizando dez pontos);

- Cinco avaliações atitudinais valendo dois pontos cada uma (total de pontos igual a dez).

- Uma avaliação bimestral, contendo dez questões de múltipla escolha, valendo dez pontos.

Nesta ficha, deve-se ter espaço para o professor colocar as competências eas habilidades que serão avaliadas pela aplicação da metodologia ABP. As observações comportamentais, chamadas de avaliações atitudinais, foram aplicadas de forma contínua durante as aulas e durante a aplicação da metodologia ABP. A continuidade é outra característica da avaliação formativa que deve estar inscrita no centro do processo educativo e formativo, proporcionando a articulação mais eficaz e constante entre a coleta de informações e a ação remediadora. Avaliações bimestrais tradicionais foram aplicadas ao fim de cada bimestre; sendo realizadas sempre posteriormente às demais avaliações (ABP e atitudinal), como uma 
atividade exigida pela coordenação pedagógica da escola. As avaliações bimestrais foram compostas por questões de exames seletivos, como os vestibulares. Para acessar essa ficha de acompanhamento do professor para as avaliações dos estudantes, bem como as questões selecionadas para este trabalho, pode-se consultar o trabalho de Silva (2017). A pontuação máxima do estudante correspondeu a 30 pontos e foi equivalente à nota máxima (nota 10).

\section{Elaboração da ficha de acompanhamento do estudante}

A ficha de controle do estudante, adaptada do trabalho de Muniz e Santinho (2007), contém a identificação do estudante e as mesmas informações da ficha de controle do professor. Essa ficha foi colada no caderno de biologia de cada estudante. Assim, cada estudante pôde registrar e acompanhar seu desempenho durante as aulas e as atividades propostas. Para que esse processo de autoavaliação fosse eficiente, incluiu-se na ficha uma tabela de controle de notas e uma explicação detalhada sobre a pontuação envolvida na autoavaliação. Esse controle de notas permitiu que o estudante acompanhasse seu desenvolvimento, sua evolução e seu desempenho durante as aulas, além de criar uma parceria entre professor e estudante. Os pais, em casa, também puderam acompanhar o desempenho de seus filhos. Dessa forma, o processo de avaliação foi transparente, formativo, integral e democrático, conforme Ramos (1998). Para acessar essa ficha de acompanhamento dos estudantes durante as aulas de biologia no ensino médio, pode-se consultar o trabalho de Silva (2017).

\section{Aplicação do Value Survey Model 1994 (VSM 94)}

As cinco dimensões culturais (IDV, MAS, PDI, UAI e LTO) desses estudantes foram determinadas por meio do modelo desenvolvido por Hofstede (1994), que baseia-se na aplicação do questionário Value Survey Model 1994 (VSM 94), que ocorreu por meio de papel impresso, com duração de 50 minutos em cada turma e sob supervisão da autora do trabalho. $O$ estudo foi teórico-empírico.

O VSM 94 apresentou 20 questões, cada qual relacionada à dimensão cultural correspondente. Em linhas gerais, as questões incluíam perguntas norteadoras, como:

a. Por favor, pense em um ensino ideal. Esqueça seu ensino atual. Ao pensar e escolher o ensino ideal, circule a resposta que melhor representa o nível de importância que teria para você cada situação proposta (8 questões);

b. Em sua vida privada, qual a importância de cada um dos seguintes aspectos para você? (4 questões);

c. Com que frequência você se sente nervoso(a) ou tenso(a) em sala de aula? (1 questão);

d. Segundo sua percepção, e não de acordo com sua situação, analise com que frequência os estudantes receiam expressar sua discordância com os professores? (1 questão);

e. Até que ponto você concorda ou discorda com cada uma das seguintes afirmações? (6 questões).

O questionário foi adaptado e validado pelo autor para se encaixar na realidade do ambiente escolar (SILVA, 2017). Cada estudante respondeu às questões, ranqueando-as de 1 a 5, sendo que a situação com maior identificação foi ranqueada em 1 e a menor em 5 . Para calcular os índices referentes às dimensões culturais, foram elaboradas planilhas eletrônicas com as equações desenvolvidas por Hofstede para cada dimensão cultural. 
Esses valores foram comparados com os resultados apresentados por Hofstede (2011), referentes aos caracterizadores da cultura organizacional brasileira, para esclarecer se os dados encontrados representam altos ou baixos índices IDV, MAS, PDI, UAI e LTO. A figura 2 apresenta as dimensões culturais de Hofstede (1994) em escala graduada de 0 a 100 pontos. Por exemplo: se o índice de individualismo versus coletivismo tiver valores próximos de 100 pontos, isso indica que há predominância da dimensão cultural individualismo. Detalhes sobre o questionário VSM 94 e de como fazer os cálculos empregados para a determinação dos índices referentes ao modelo de Hofstede (1994) podem ser obtidos em Silva (2017). Durante a aplicação desse questionário, os estudantes responderam também questões sobre dados pessoais e preferências ao estudo.

Figura 2 - Dimensões culturais de Hofstede em escala graduada que vai de 0 a 100 pontos

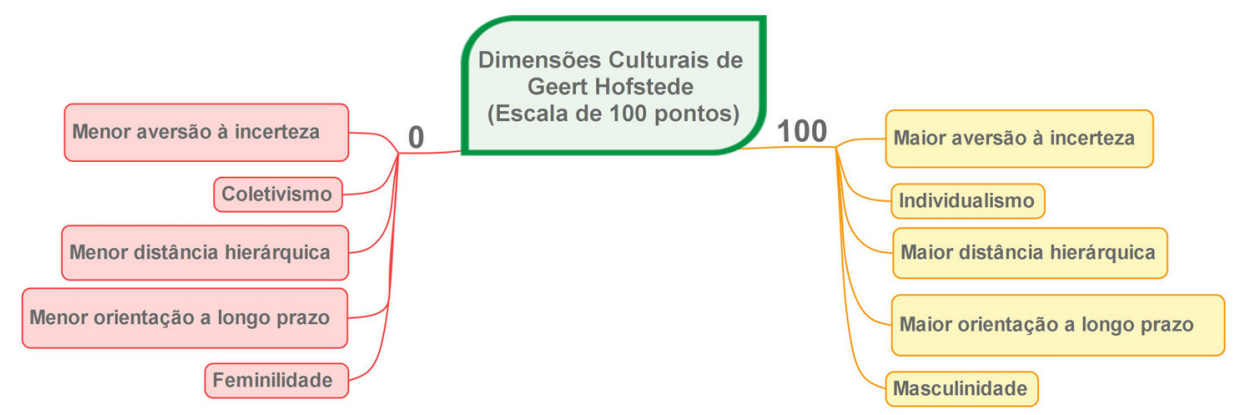

Fonte: Elaborado pelos autores.

\section{Processos 3 e 5: Interpretação da informação e regulação da aprendizagem}

Os últimos processos incluídos no modelo estrutural de ações e estratégias para analisar a avaliação formativa (ANTONIOU; JAMES, 2014) referem-se às decisões dos professores e às ações subsequentes para moderar o ensino e a aprendizagem. A regulação da aprendizagem é o processo de alterar futuras atividades ou estratégias de aprendizagem com base nas informações coletadas. Nesta proposta, esses processos foram facilitados com a interpretação dos dados coletados nas fichas de auxílio do professor durante as avaliações atitudinais (figura 1) de acompanhamento do professor e dos estudantes, bem como com o conhecimento do perfil cultural das turmas que, de certa forma, serviram de apoio para a conduta do professor no processo de mediação e também para melhor entendimento do comportamento dos estudantes no ambiente escolar.

Para determinar o desempenho dos estudantes nas avaliações ABP, atitudinal e bimestral, nos três bimestres em que essa metodologia foi implementada, foram utilizadas planilhas do software Excel para calcular e correlacionar esses resultados. Também foi feita a análise estatística dos dados, através do programa Statgraphics, versão 6.0. Os resultados foram expressos em tabelas de estimativas dos efeitos, desvio-padrão e tabelas de análise de variância com colunas de coeficiente de variação (CV), graus de liberdade (GL), soma de quadrados (SQ), quadrado médio (QM), teste $F(A N O V A)$ e nível de significância (p-valor).

\section{Resultados e Discussão}

A pesquisa foi organizada de acordo com o modelo estrutural de ações e estratégias para analisar a avaliação formativa (ANTONIOU; JAMES, 2014), que surgiu dos objetivos de 
explorar o que o professor faz como prática formativa de avaliação e também de compreender a lógica dos professores em suas ações e atitudes em relação à avaliação formativa no ensino fundamental. Nesta análise, surge uma estrutura de dados observacionais que baseia-se em uma sequência de cinco processos inter-relacionados, comuns a todas as ocorrências de avaliação formativa: (1) comunicação de expectativas e critérios de sucesso; (2) obtenção e coleta de informações; (3) interpretação da informação/julgamento; (4) fornecimento de feedback; e (5) ação/regulação da aprendizagem.

\section{Modelo estrutural de ações e estratégias para analisar a avaliação formativa}

\section{Processo 1: Comunicação de expectativas e critérios de sucesso}

O processo 1 foi facilitado com o uso de competências e habilidades na resolução de problema como critérios de sucesso em uma avaliação formativa com base na metodologia ABP. No entanto, identificar as competências e as habilidades em uma lição ou tarefa consistentemente mostra-se uma atividade laboriosa, se não for consultado um material didático que já as contenha.

\section{Processos: obtenção e coleta de informações, interpretação da informação, fornecimento de feedback e ação para regular a aprendizagem}

De acordo com Antoniou e James (2014), o terceiro processo, isto é, a interpretação da informação (ou o julgamento) é uma atividade mental que não pode ser contemplada durante as observações em sala de aula, pois a avaliação formativa, como toda medida educacional, é um processo inferencial, porque os professores não podem saber com certeza qual entendimento existe dentro da cabeça de um estudante. No entanto, os resultados dessa interpretação são observáveis por meio do fornecimento de feedback (processo 4) que dá início à ação para regular o ensino e a aprendizagem (processo 5).

No geral, a partir dos dados pessoais e das preferências de estudos dos 55 estudantes, constatou-se que $60 \%$ e $40 \%$ foram dos sexos masculino e feminino, respectivamente. A faixa etária foi entre 15 e 19 anos. Também foi possível constatar que, ao término do ensino médio, $12 \%$ desses estudantes pretendem somente continuar estudando, enquanto a minoria (3\%) pretende parar de estudar e a maioria (69\%) pretende trabalhar e estudar; $14 \%$ desses estudantes estão indecisos com relação ao que fazer depois do ensino médio.

Com relação à área que esses estudantes teriam maior identificação, 27\% preferem a área de humanas, $23 \%$ a de exatas e $16 \%$ a de ciências biológicas, enquanto 32\% não sabem. Outras informações também importantes foram observadas, mostrando que 30\% dos estudantes já foram reprovados uma vez ou mais de uma vez. Somente $25 \%$ dos estudantes têm o hábito de ler material não passado pelos professores. Todos os estudantes sempre estudaram em escolas públicas.

No processo de obtenção e coleta de informações, práticas como a metodologia ABP e as dimensões culturais de Hofstede (1994) foram propostas para ajudar o professor em sala de aula a implementar o processo de avaliação formativa. No entanto, como há interrelação entre os cinco processos, estes foram discutidos simultaneamente. Nesta discussão, incluíram-se os resultados quantitativos do fornecimento de feedback e as ações que foram tomadas para regular o processo ensino-aprendizagem. 
Determinação do perfil cultural dos estudantes empregando-se o modelo de dimensão cultural proposto por Geert Hofstede

O conhecimento das dimensões culturais das turmas de estudantes facilitou a conduta do professor em sala de aula e as ações que foram tomadas para regular o processo ensinoaprendizagem - como pode ser verificado a seguir.

\section{Índice de distância hierárquica (PDI)}

O PDI sugere o grau que as pessoas esperam e endossam como o poder ou a autoridade seja distribuído em uma sociedade (HOFSTEDE, 2016). Como exemplo, em sala de aula, o PDI pode afetar a forma como os estudantes visualizam professores, instituições, conhecimento, etc. Com relação ao PDI, o Brasil apresenta índice de 69, que corresponde a moderadamente alto. Em contraste, os estudantes do ensino médio, em ambas as turmas ( $A$ e B), apresentaram baixo PDI, de -24 e -13 (índices negativos), respectivamente. Lembrando que, em uma sociedade com pequena distância hierárquica, a desigualdade de tratamento entre as pessoas é pequena, o que favorece a interdependência entre os que detêm mais poder e os que têm menos poder (HOFSTEDE, 2012, 2016).

Com relação à sala de aula, os baixos valores encontrados em ambas as turmas, para esta dimensão cultural, indicavam que os estudantes teriam a tendência em tratar os professores como iguais, ou seja, sem receio em conversar e apresentar sua opinião, mantendo sempre o respeito e a interdependência. A interdependência positiva consiste na criação de situações em que os estudantes trabalham em conjunto para maximizar a aprendizagem de todos, partilhando os recursos e alcançando juntos o sucesso. Este elemento é central, pois os estudantes devem acreditar que cada um só é bem-sucedido se todos o forem (SIMÕES, 2012).

Neste sentido, a professora buscou a participação dos estudantes para facilitar a interdependência e a tendência ao 'bom' diálogo, constatando que, em ambas as turmas, os estudantes realmente arguíam mais entre si e com ela - o que facilitou o processo ensino-aprendizagem desses estudantes. Foi possível observar também o contentamento dos estudantes após essa dinâmica. Ao contrário do observado, nas turmas com índices de distância hierárquica elevados, pressupõe-se também a participação dos estudantes, porém sem contradizer o professor, mesmo não concordando - o que, provavelmente, diminuiria consideravelmente o desenvolvimento da autonomia. Neste caso, deve-se buscar alternativas para o envolvimento maior dos estudantes.

\section{Individualismo versus coletivismo (IDV)}

Com relação ao IDV, o Brasil é avaliado como uma cultura coletivista, segundo Hofstede (2011), apresentando índice baixo - de 38 pontos. Entre os estudantes do ensino médio, tanto na Turma A quanto na $B$, também foram encontrados índices baixos de IDV - de 1,43 e 6,15 pontos, respectivamente. Esta dimensão diz respeito ao índice de individualismo versus coletivismo e considera o nível de integração das pessoas em grupo dentro de uma sociedade. Nas sociedades com baixo IDV ou coletivista, tudo é integrado - as pessoas se veem pertencendo a grupos. Como aspecto positivo, as turmas de estudantes apresentaram alto índice de coletivismo, ou seja, baixo índice de individualismo, indicando que, para o 
processo de ensino-aprendizagem, seria vantajoso estimular o trabalho em grupo, tanto na turma A como na B.

A tabela 1 apresenta os dados estatísticos dos resultados da resolução de problemas em grupo (aplicação da ABP) e individual (logo após a atividade ABP), respectivamente. Para a análise dos dados, as turmas $A$ e $B$ foram analisadas em conjunto, por terem apresentado perfis similares (baixo índice de individualismo). As notas foram atribuídas a cada estudante no formato 'certo ou errado', de acordo com as competências envolvidas na atividade - pelo qual, os que não atingiram as competências exigidas foram pontuados com zero e os que conseguiram atingir essas competências receberam nota dez.

Tabela 1 - Dados estatísticos entre os bimestres para a metodologia de aprendizagem baseada em problemas (ABP) e a atividade individual

\begin{tabular}{|c|c|c|c|c|c|c|c|c|c|}
\hline Atividades & $\begin{array}{c}\text { Estudantes } \\
\text { (Bimestre) }\end{array}$ & $\begin{array}{l}\text { Número de } \\
\text { estudantes }\end{array}$ & $\begin{array}{l}\text { Média do } \\
\text { Bimestre }\end{array}$ & $\begin{array}{c}\text { Grupo } \\
\text { Homogê- } \\
\text { neo* }\end{array}$ & $\begin{array}{l}\text { Desvio } \\
\text { padrão }\end{array}$ & $\begin{array}{c}\text { Coeficiente } \\
\text { de variação } \\
(\%)\end{array}$ & Mínimo & Máximo & Faixa \\
\hline \multirow{4}{*}{$\begin{array}{l}\text { Grupo } \\
\text { (Aplicação } \\
\text { da ABP) }\end{array}$} & Primeiro & 51 & 5,88235 & $x$ & 3,42139 & 58,16366 & 0,0 & 10,0 & 10 \\
\hline & Segundo & 52 & 6,34615 & $x$ & 3,30113 & 52,01784 & 0,0 & 10,0 & 10 \\
\hline & Terceiro & 41 & 8,04878 & $x$ & 3,33130 & 41,38889 & 0,0 & 10,0 & 10 \\
\hline & Total & 144 & 6,66667 & & 3,44791 & 51,71862 & 0 & 10,0 & 10,0 \\
\hline \multirow{4}{*}{$\begin{array}{l}\text { Individual } \\
\text { (após ABP) }\end{array}$} & Primeiro & 51 & 3,72549 & $x$ & 3,13738 & 84,21389 & 0 & 10,0 & 10 \\
\hline & Segundo & 52 & 7,40385 & $x$ & 3,05029 & 41,19870 & 0 & 10,0 & 10 \\
\hline & Terceiro & 41 & 7,43902 & $x$ & 4,20148 & 56,47894 & 0 & 10,0 & 10 \\
\hline & Total & 144 & 6,11111 & & 3,85236 & 63,03863 & 0 & 10,0 & 10 \\
\hline
\end{tabular}

*As letras " $X$ " alinhadas na coluna formam grupos de médias aritméticas em que não há diferença significativa entre elas no nível de $95 \%$ de confiança.

Fonte: Elaborada pelos autores.

$\mathrm{Na}$ tabela 1 observa-se que as médias aritméticas aumentaram no decorrer dos bimestres, independentemente da resolução do problema em grupo ou individualmente, o que demonstra que a intervenção do professor através deste procedimento foi informativa, atingindo o objetivo da avaliação formativa - que é justamente fazer com que o estudante perceba e tome consciência de suas dificuldades e seja capaz de reconhecer e corrigir seus próprios erros.

A avaliação formativa, como se espera, foi realizada de forma contínua nos bimestres, durante as aulas, proporcionando a articulação mais eficaz e constante entre coleta de informações e ação remediadora - o que provavelmente contribuiu para a observação da melhora no desempenho dos estudantes durante a evolução nos bimestres. Vemos na tabela 1 que, conforme a evolução nos bimestres, e como cada estudante recebeu uma nota separadamente no grupo, foi possível constatar diminuição no coeficiente de variação para as atividades em grupo (aplicação da ABP), indicando que houve, em termos de notas dadas aos estudantes, maior homogeneização dos resultados obtidos. Concomitantemente, houve aumento nas médias bimestrais nos grupos. Neste caso, no terceiro bimestre, notouse melhoria na média aritmética no grupo, com diferença significativa no nível de $95 \%$ de confiança com relação aos demais bimestres.

Além disso, observou-se que, na atividade individual, que foi aplicada pela primeira vez (primeiro bimestre), a média aritmética dos estudantes foi menor, em comparação aos outros bimestres, no nível de $95 \%$ de confiança. Nos bimestres posteriores, não se observou diferença significativa neste nível (tabela 1). No geral, o coeficiente de variação $(51,72 \%)$ 
da atividade em grupo foi menor do que o coeficiente de variação $(63,04 \%)$ da atividade individual (tabela 1) - o que indica que as notas dos estudantes na atividade em grupo (ABP) apresentaram-se mais homogêneas do que na atividade individual; ou seja, os estudantes em grupo conseguiram mais notas próximas, um dos outros, do que quando realizaram a resolução do mesmo problema individualmente. Como essas notas estão vinculadas a acertos e erros de competências adquiridas, os estudantes, ao resolverem o problema individualmente, apresentaram maior discrepância entre acertos e erros do que quando realizaram a atividade em grupo (ABP).

A análise de variância dos dados (ANOVA) foi realizada para as atividades em grupo (aplicação da ABP) e individual (após aplicação da ABP) e mostrou que há diferença estatisticamente significativa entre as médias dos dois grupos (entre os bimestres e dentro do bimestre) no nível de significância de 5\%, tanto para a atividade em grupo como para a atividade individual. Como mencionado, as médias aritméticas foram favorecidas no decorrer dos bimestres, tanto nas atividades em grupo como nas individuais.

\section{Masculinidade versus feminilidade (MAS)}

O MAS refere-se principalmente à distribuição de papéis emocionais dentro da sociedade. Em suma, quanto mais os papéis são tradicionalmente orientados e competitivos, haverá predominância 'masculina'; o inverso, 'feminina', refere-se quando os níveis de assertividade, competitividade e carinho são mais compartilhados entre as pessoas (HOFSTEDE, 2016). Em sala de aula, pode afetar o nível de competição ou colaboração exibida pelos estudantes. Com relação ao MAS, segundo Hofstede (1980), a sociedade brasileira apresenta índice moderadamente baixo de masculinidade (49 pontos) ou leve predominância pela dimensão da feminilidade. No entanto, os estudantes pesquisados apresentaram esse índice moderadamente elevado (65,9 pontos), na Turma A, e baixo ( 24,5 pontos) na Turma B.

No caso da Turma B, os estudantes apreciam a 'simpatia' do professor, enquanto que, na Turma A, apreciam a sua'excelência'. Como característica cultural, a Turma A tem predisposição a resolver os conflitos por meio de confrontos, com possível existência de competição entre os colegas. Neste caso, para a Turma A, como o índice de masculinidade dos estudantes foi elevado, a professora precisou de uma postura decisiva e, ao mesmo tempo, teve que direcionar suas aulas e atividades, estimulando desafios e reconhecendo o avanço de seus estudantes. Na aplicação da ABP, foi observado que os estudantes da Turma A, por apresentarem perfil de masculinidade mais elevado, foram mais competitivos do que os estudantes da Turma B, pois os estudantes da Turma A comparavam e discutiam os pontos e as notas entre eles.

\section{Índice de aversão à incerteza (UAI)}

Com relação ao UAI, a sociedade brasileira apresenta alto índice de aversão à incerteza (76 pontos). No caso dos estudantes, este índice foi elevado $(93,1$ pontos), para a Turma B, e baixo (16,2 pontos) para a Turma $A$.

Conforme Nóbrega (2013), seres humanos, naturalmente, sofrem ansiedade por não saberem como será o dia de amanhã. O futuro é incerto e esta dimensão mede o grau de inquietude dos habitantes em relação a situações desconhecidas (HOFTSTEDE, 2001). Dentre os aspectos salientáveis, com relação ao UAI, no caso da Turma A, em que esse índice foi baixo, 
os estudantes a preciam um educador'flexível', com o qual as discussões sejam parte integrante do processo de aprendizagem, enquanto os estudantes da Turma B são confortáveis em situações de aprendizagem estruturadas e estão preocupados com respostas certas. Nesse sentido, em ambas as turmas, o professor atuou para favorecer as atividades de avaliação desses estudantes.

\section{Orientação de longo prazo versus orientação normativa de curto prazo (LTO)}

Com relação ao LTO, o Brasil apresenta esse índice moderadamente elevado (62 pontos), enquanto os estudantes deste trabalho apresentaram, para ambas as salas, índices moderadamente baixos - de 42,1 e 41,5, para as turmas A e B, respectivamente. Este índice cultural foi muito similar para as duas turmas. As sociedades com alto índice de LTO apresentam altos valores para educação e trabalho, mostrando respeito pelas tradições, perseverança, lealdade e compromisso. Por outro lado, sociedades com baixo LTO promovem-se pela igualdade, alta criatividade e individualismo (HOFTSTEDE, 2001).

O uso das dimensões culturais de Hofstede (1994), pelo professor, auxiliou na obtenção de um diagnóstico das duas turmas e favoreceu uma intervenção diferenciada nas turmas. Além disso, o progresso na aprendizagem de cada estudante tem um ritmo diferente. Segundo Perrenoud (1999), não há avaliação formativa sem diferenciação, já que todo público escolar, por mais selecionado que seja, é heterogêneo.

\section{Desempenho dos estudantes nas avaliações: $A B P$, atitudinal e bimestral}

A avaliação formativa dos estudantes foi realizada de forma contínua através das avaliações atitudinais que também foram associadas à metodologia ativa ABP. Os resultados das avaliações ABP apresentados na tabela 2 diferenciam-se ligeiramente dos resultados da tabela 1, pois levaram em consideração a avaliação atitudinal durante a aplicação do ABP.

No caso da tabela 1, somente foi avaliado se os estudantes acertaram ou erraram (com base das competências) as resoluções dos problemas - em grupo ou individualmente.

Tabela 2 - Dados estatísticos do desempenho dos estudantes nas avaliações: aprendizagem baseada em problemas (ABP), atitudinal e bimestral durante três bimestres consecutivos

\begin{tabular}{|c|c|c|c|c|c|c|c|c|c|}
\hline $\begin{array}{c}\text { Tipo de } \\
\text { Avaliação }\end{array}$ & $\begin{array}{l}\text { Grupo de } \\
\text { estudantes } \\
\text { (Bimestre) }\end{array}$ & $\begin{array}{l}\text { Número de } \\
\text { estudantes }\end{array}$ & $\begin{array}{l}\text { Média do } \\
\text { Bimestre }\end{array}$ & $\begin{array}{c}\text { Grupo } \\
\text { Homogê- } \\
\text { neo** }\end{array}$ & $\begin{array}{l}\text { Desvio } \\
\text { padrão }\end{array}$ & $\begin{array}{c}\text { Coeficiente } \\
\text { de variação } \\
(\%)\end{array}$ & Mínimo & Máximo & Faixa \\
\hline \multirow{4}{*}{$A B P^{*}$} & Primeiro & 51 & 5,23529 & $x$ & 2,4132 & 46,09487 & 2,0 & 10,0 & 8,0 \\
\hline & Segundo & 52 & 6,84616 & $x$ & 2,45257 & 35,82402 & 2,0 & 10,0 & 8,0 \\
\hline & Terceiro & 41 & 8,70732 & $x$ & 2,18225 & 25,06225 & 5,0 & 10,0 & 5,0 \\
\hline & Total & 144 & 6,80556 & & 2,72589 & 40,05387 & 2,0 & 10,0 & 5,0 \\
\hline \multirow{3}{*}{ Atitudinal } & Primeiro & 55 & 5,89091 & $x$ & 2,53620 & 43,05277 & 2,0 & 10,0 & 8,0 \\
\hline & Segundo & 54 & 7,55556 & $x$ & 1,96830 & 26,05101 & 2,0 & 10,0 & 8,0 \\
\hline & Terceiro & 50 & 7,48000 & $x$ & 2,48456 & 33,21604 & 2,0 & 10,0 & 8,0 \\
\hline \multirow{5}{*}{ Bimestral } & Total & 159 & 6,95597 & & 2,48456 & 35,71838 & 2,0 & 10,0 & 8,0 \\
\hline & Primeiro & 43 & 4,37209 & $x$ & 2,38071 & 54,45245 & 1,0 & 10,0 & 9,0 \\
\hline & Segundo & 48 & 4,75000 & $x$ & 2,13880 & 45,02737 & 1,0 & 9,0 & 8,0 \\
\hline & Terceiro & 50 & 9,58000 & $x$ & 1,23040 & 12,84342 & 5,0 & 10,0 & 5,0 \\
\hline & Total & 141 & 6,34752 & & 3,09304 & 48,72832 & 1,0 & 10,0 & 9,0 \\
\hline
\end{tabular}

*ABP em grupo e com avaliação atitudinal.

**As letras " $X$ " alinhadas na coluna formam grupos de médias aritméticas em que não há diferença significativa entre elas no nível de $95 \%$ de confiança.

Fonte: Elaborada pelos autores. 
Considerando-se também a avaliação atitudinal durante a aplicação do ABP, observase com maior facilidade a ocorrência de melhorias nas médias dos estudantes no decorrer dos bimestres. Na tabela 2, verifica-se que as médias bimestrais dos estudantes foram estatisticamente diferentes no nível de $95 \%$ de confiança. Com relação às outras avaliações (atitudinal e bimestral), observam-se também melhorias nos resultados das médias bimestrais no nível de $95 \%$ de confiança. No entanto, esse favorecimento na avaliação atitudinal ocorreu a partir do segundo bimestre de aplicação desta metodologia, se estabilizando, posteriormente, com médias em torno de 7,5. Esse resultado indicou que foi possível observar favorecimento de $27,11 \%$ no comportamento desses estudantes em sala de aula com a aplicação desta metodologia (tabela 2).

Surpreendentemente, foi o resultado na avaliação bimestral que, praticamente, mais que duplicou a média $(9,58)$ no terceiro bimestre de aplicação desta metodologia - em relação aos primeiro e segundo bimestres que apresentaram médias bimestrais estagnadas em torno de 4,56. Neste caso, observou-se que o coeficiente de variação foi de apenas 12,84\%, ou seja, indicando que as médias, apesar de variarem entre valores de 5 a 10, apresentaram-se mais homogêneas dentro daquele bimestre do que nos outros bimestres (tabela 2).

No geral, pode-se observar que, pela primeira vez, a aplicação da metodologia apresentou, em todas as avaliações, maiores variações em médias bimestrais e atitudinais. Fato constatável pelos valores elevados nos coeficientes de variação do primeiro bimestre em relação aos outros bimestres consecutivos para a aplicação desta metodologia. Essa variação entre as médias bimestrais foi progressiva e contínua na avaliação da ABP, mostrando a evolução no desempenho desses estudantes ao longo do processo de implementação dessa metodologia, o que favoreceu também o desempenho dos estudantes durante as avaliações atitudinais e bimestrais. A análise de variância dos dados (ANOVA) foi realizada para os resultados das avaliações $A B P$, incluindo avaliação atitudinal, e também para as avaliações atitudinal e bimestral. A ANOVA mostrou que há diferença estatisticamente significativa entre as médias dos dois grupos no nível de significância de 5 \% para todos os tipos de avaliações.

No entanto, como a atribuição de nota foi exigência do sistema, a postura avaliativa, conforme Harres (2016), percorreu um nível intermediário (nível 4) entre classificatória e formativa. Segundo Harres (2016), a escala de níveis pode seguir do nível 1 (totalmente classificatório) atingindo o nível 7 (totalmente formativo, no qual há desvinculação entre avaliação e atribuição de nota). No nível 4, atribui-se uma nota e esta tem relação com o compromisso, com a qualidade dos trabalhos e com as ideias finais apresentadas, diferenciando-se as notas entre os estudantes, por exemplo, através da autoavaliação individual e coletiva dos próprios estudantes e a avaliação do professor. Para esse autor, esta evolução na prática avaliativa, correspondente ao nível 4 (intermediário), procede na avaliação do crescimento dos estudantes e do desenvolvimento das aulas e começa a haver diferenciação entre avaliação e classificação dos estudantes.

\section{Conclusões}

A implementação da avaliação formativa no ensino médio foi favorecida pelo uso do modelo estrutural composto pelos processos inter-relacionados:comunicação de expectativas e critérios de sucesso; obtenção e coleta de informações; interpretação da informação; fornecimento de feedback; e regulação da aprendizagem. Como há inter-relação entre esses cinco processos, eles foram discutidos simultaneamente, incluindo-se os resultados 
quantitativos do fornecimento de feedback e as ações que foram tomadas para regular os processo de ensino-aprendizagem. A inserção, neste modelo, das práticas metodologia de aprendizagem baseada em problemas (ABP) e dimensões culturais de Hofstede mostrouse uma estratégia de ação facilitadora para a implementação da avaliação formativa e diagnóstica em sala de aula. O uso do perfil cultural de Geert Hofstede, pelo professor, auxiliou na obtenção de um diagnóstico das duas turmas e favoreceu a intervenção diferenciada. A proposta de avaliação formativa integrada com a ABP no ensino médio melhorou o desempenho dos estudantes em aspectos comportamentais e até mesmo na avaliação classificatória - que aqui está representada pela avaliação bimestral. No entanto, como a atribuição de nota foi exigência do sistema, a postura avaliativa percorreu um nível intermediário entre classificatória e formativa - pela escala proposta por Harres (2016). Esta proposta foi disponibilizada aos professores interessados em sua aplicação no ensino médio (escola pesquisada). O uso das fichas e do questionário VSM 94 por outro profissional da área foi positivo, sendo mencionadas sua praticidade e sua viabilidade. Também foi possível apoiar a implementação desta metodologia no plano pedagógico da escola pesquisada, proporcionando reuniões com os professores para esclarecimento e suporte.

\section{Referências}

ANTONIOU, P.; JAMES, M. Exploring formative assessment in primary school classrooms: Developing a framework of actions and strategies. Educational Assessment, Evaluation and Accountability, Dordrecht, v. 26, n. 2, p. 153-176, 2014.

BARROS FILHO, J.; SILVA, D. Algumas reflexões sobre a avaliação dos estudantes no ensino de Ciências. Ciência \& Ensino, Piracicaba, v. 9, p. 14-17, 2000.

BRASIL. Lei de diretrizes e bases da educação nacional. 10. ed. Brasília: Câmara dos Deputados, 2014. v. 6.

ESTRELA, A.; NÓVOA, A. Avaliações em educação: novas perspetivas. Porto: Porto Editora, 2003.

HARRES, J. B. S. Desvinculação entre avaliação e atribuição de nota: análise de um caso no ensino de física para futuros professores. Ensaio: pesquisa em educação em ciências, Belo Horizonte, v. 5, n. 1, p. 42-51, 2016.

HENDRY, G. D.; FROMMER, M.; WALKER, R. A. Constructivism and problem-based learning. Journal of Further and Higher Education, London, v. 23, n. 3, p. 369-371, 1999.

HOFSTEDE, G. The business of international business is culture. International Business Review, Dordrecht, v. 3, n. 1, p. 1-14, 1994.

HOFSTEDE, G. Comparing values, behaviors, institutions and organizations across nations. Thousand Oaks: Sage, 2001.

HOFSTEDE, G. Culturas nacionales, culturas organizacionales y el papel de la gestión empresarial. In: VALORES y etica para el siglo XXI. Madrid: BBVA, 2012. p. 413-433.

HOFSTEDE, G. Dimensionalizing cultures: the hofstede model in context. Online Readings in Psychology and Culture, Melbourne, Fl, v. 2, n. 1, p. 1-26, 2011.

HOFSTEDE, G. Motivation, leadership, and organization: do American theories apply abroad? Organizational Dynamics, New York, v. 9, n. 1, p. 42-63, 1980. 
MELO, R. C. Estratégias de ensino e aprendizagem baseadas em problemas (PBL) no ensino tecnológico. Revista Tekhne e Logos, Botucatu, v. 5, n. 1, p. 69-84, 2014.

MUNIZ, M. I. S.; SANTINHO, M. S. Uma avaliação formativa na sala de aula. [2007]. Disponível em: https://tinyurl.com/y9cygc68. Acesso em: 14 feb. 2019.

NÓBREGA, A. H. F. Análise das dimensões culturais do centro acadêmico Armando de Salles Oliveira. 2013. 95 f. Trabalho de conclusão de curso (Graduação em Engenharia Mecânica) - Escola de Engenharia de São Carlos, Universidade de São Paulo, São Carlos, 2013.

PAULA-SILVA, J. M. A. Cultura escolar, autoridade, hierarquia e participação: alguns elementos para reflexão. Cadernos de Pesquisa, São Paulo, n. 112, p. 125-135, 2001.

PERÉZ GOMÉZ, A. I. A. A cultura escolar na sociedade neoliberal. Porto Alegre: Artmed, 2001.

PERRENOUD, P. Avaliação: da excelência à regulação das aprendizagens: entre duas lógicas. Porto Alegre: Artmed, 1999.

RAMOS, R. Y. Temas transversais: a escola da ultramodernidade. Pátio: revista pedagógica, Porto Alegre, n. 5, p. 1-6, 1998.

RODRÍGUEZ PALMERO, M.; MOREIRA, M. Modelos mentales de la estructura y del funcionamiento de la célula: dos estudios de casos. Investigações em Ensino de Ciências, Porto Alegre, v. 4, n. 2, p. 121 160, 1999.

SANT'ANNA, I. M. Por que avaliar? como avaliar?: critérios e instrumentos. 3. ed. Petrópolis: Vozes, 1995.

SANTANA, D. L.; MENDES, G. A.; MARIANO, A. M. Estudo das dimensões culturais de Hofstede: análise comparativa entre Brasil, Estados Unidos e México. C@lea: revista cadernos de aulas do LEA, Ilhéus, n. 3, p. 1-13, 2014.

SÃO PAULO (ESTADO). Secretaria da Educação. Currículo do estado de São Paulo: ciências da natureza e suas tecnologias. São Paulo: SE, 2011. Disponível em: https://tinyurl.com/yagecgry. Acesso em: 18 jun. 2020.

SILVA, F. C. Proposta de avaliação formativa aplicando aprendizagem baseada em problemas (ABP) no ensino médio. 2017. Dissertação (Mestrado em Ciências) - Escola de Engenharia de Lorena, Universidade de São Paulo, Lorena, 2017.

SIMÕES, S. E. F. "Um por todos e todos por um": fomentar a aprendizagem cooperativa do inglês no $1^{\circ}$ CEB. 2012. Dissertação (Mestrado em Ciências da Educação) - Instituto de Educação, Universidade do Minho, Braga, 2012. 